\title{
On infinite systems of differential equations with deviated argument I
}

\author{
by Bogdan Rzepeciu (Poznaú)
} \begin{abstract}
and umiqueness of the solution of tho system

$$
\begin{aligned}
& x_{n}^{\prime}(t)=f_{n}\left[t ; x_{1}(t), x_{1}\left(\varphi_{1}^{(\mathrm{i})}(t)\right), x_{1}\left(\varphi_{2}^{(1)}(t)\right), \ldots ;\right. \\
& x_{2}(t), x_{2}\left(\varphi_{1}^{(2)}(t)\right), x_{2}\left(\varphi_{2}^{(2)}(t)\right), \ldots ; \ldots \\
& \ldots \ldots \ldots \ldots \ldots \\
& x_{1}^{\prime}(t), x_{1}^{\prime}\left(\psi_{1}^{(1)}(t)\right), x_{1}^{\prime}\left(\psi_{2}^{(1)}(t)\right), \ldots ; \\
& x_{2}^{\prime}(t), x_{2}^{\prime}\left(\psi_{1}^{(2)}(t)\right), x_{2}^{\prime}\left(\psi_{2}^{(2)}(t)\right), \ldots ; \ldots \\
& \ldots \ldots \ldots \ldots \ldots \\
& (n=1,2, \ldots)
\end{aligned}
$$

Abstract. The aim of this paper is to indicato some effect caused by the deviated argument in infinite systems of differential equations. We give theorems on existence

with initial conditions $x_{n}(0)=0, n=1,2, \ldots$

In [2] a discussion is made on the existence and uniqueness of the solution of the differential equation .

$$
x^{\prime}(t)=f\left[t, \infty(t), \infty\left(\varphi_{1}(t)\right), \ldots, x\left(\varphi_{n}(t)\right), x^{\prime}(t), x^{\prime}\left(\psi_{1}(t)\right), \ldots, \infty^{\prime}\left(\psi_{m}(t)\right)\right]
$$

with the initial condition $x(0)=0$. The purpose of this paper is to point out some effects which the doviated argument causes on infinite systems of differential equations.

Infinite systems of differential equations were considered by $A$. $N$. Tichonov [7], [8], and K. P. Persidski [5], [6]. Results of these authors are generalized in [9] for the systems of equations whose right-hand sides contain also variable parameters. Infinite systems of integral-differential equations were studied in [3].

The purpose of this paper is to discuss the existenco and uniqueness problems for infinite system of differential equations

$$
\begin{aligned}
x_{n}^{\prime}(t)=f_{n}[t ; & x_{1}(t), x_{1}\left(\varphi_{11}(t)\right), x_{1}\left(\varphi_{12}(t)\right), \ldots ; \\
& x_{2}(t), x_{2}\left(\varphi_{21}(t)\right), x_{2}\left(\varphi_{22}(t)\right), \ldots ; \ldots \\
& \ldots \ldots \ldots \ldots \ldots \ldots \\
& x_{1}^{\prime}(t), x_{1}^{\prime}\left(\psi_{11}(t)\right), x_{1}^{\prime}\left(\psi_{12}(t)\right), \ldots ; \\
& \left.x_{2}^{\prime}(t), x_{2}^{\prime}\left(\psi_{21}(t)\right), x_{2}^{\prime}\left(\psi_{22}(t)\right), \ldots ; \ldots\right]
\end{aligned}
$$

with initial conditions $x_{n}(0)=0, n=1,2, \ldots$

$$
(n=1,2, \ldots)
$$


In the proofs of existence of at least one solution for the above stated problem we use the following form of Tichonov's fixed point theorem: If in $B_{0}$-space a continuous operator maps a closed conven and compact set into itself, then it has a fiased point.

1. Let $s$ denote the space of all sequences of real numbers with the usual metrics $\underline{a}$. The sets

$$
s_{1}=s \times s \times \ldots, \quad s_{2}=[0, a] \times s_{1}, \quad s_{3}=[0, a] \times s_{1} \times s_{1}
$$

are considered with the "product" metrics $\varrho_{1}, \varrho_{2}$ and $\varrho_{3}$ respectively.

Let $\|\cdot\|$ be a norm in $C[0, a]$. In the vector space $E=C[0, a] \times$ $\times C[0, a] \times \ldots$ define a sequence $\left(p_{n}\right)$ of semi-norms $p_{n}(\Phi)=\left\|p_{n}\right\|$, where $\Phi=\left(\varphi_{1}, \varphi_{2}, \ldots\right)$. Then (cf. [1]) the functional $\|\cdot \cdot\|$ defined by

$$
\|\Phi\|=\sum_{1}^{\infty} 2^{-n} \frac{\left\|\varphi_{n}\right\|}{1+\left\|\varphi_{n}\right\|}
$$

is a paranolm in $E$. It is known (see [4]) that the space $E$ equipped with this paranorim is a $B_{0}$-space.

The convergence in the introduced spaces is equivalent to the coordinate-twise convergence. Given a non-negative constant $R$, let $m_{R}$ be the set of real sequences bounded by $R$. Then evidently the product $Z=m_{R_{1}} \times$ $\times m_{R_{2}} \times \ldots$ is a compact subset of $s_{1}$. Let $\bar{a}=(\bar{t}, \bar{\xi}) \in s_{2}$, where $\bar{\xi}=\left(\bar{u}_{n}\right)$ $\epsilon s_{1}, \bar{u}_{i}=\left(\bar{u}_{i n}\right) \epsilon s$. A function $f: s_{2} \rightarrow(-\infty, \infty)$ is continuous at the point $\bar{a}$ if and only if, for every $\varepsilon>0$ a number $\eta>0$ and natural numbers $N_{1}, N_{2}, \ldots, N_{M}$ exist such that

$$
\left|f\left(t ; u_{11}, u_{12}, \ldots ; \ldots\right)-f\left(\bar{t} ; \bar{u}_{11}, \bar{u}_{12}, \ldots ; \ldots\right)\right|<\varepsilon,
$$

whenever $|t-\bar{t}|<\eta,\left|u_{k i}-\bar{u}_{k i}\right|<\eta$ for $i=1,2, \ldots, N_{k}, k=1,2, \ldots, M r$. If $\bar{A}=(\bar{t}, \bar{\xi}, \bar{\eta}) \in s_{3}, \bar{\xi}=\left(\bar{u}_{n}\right), \bar{\eta}=\left(\bar{v}_{n}\right) \in s_{1}, \bar{u}_{i}=\left(\bar{u}_{i n}\right), \bar{v}_{i}=\left(\bar{v}_{i n}\right) \epsilon \mathcal{s}$, then a function $F: s_{3} \rightarrow(-\infty, \infty)$ is continuous at the point $\bar{A}$ if and only if for every $\varepsilon>0$ there exist a number $\eta>0$ and natural numbers $N_{1}, N_{2}, \ldots$ $\ldots, N_{M}$ and $N_{1}^{\prime}, N_{2}^{\prime}, \ldots, N_{K}^{\prime}$ such that

$$
\left|F\left(t ; u_{11}, u_{12}, \ldots ; v_{11}, v_{12}, \ldots\right)-F\left(\bar{t} ; \bar{u}_{11}, \bar{u}_{12}, \ldots ; \bar{v}_{11}, \bar{v}_{12}, \ldots\right)\right|<\varepsilon,
$$

when $|t-\bar{t}|<\eta, \quad\left|u_{k i}-\bar{u}_{k i}\right|<\eta$ for $i=1,2, \ldots, N_{k i}, \quad \pi=1,2, \ldots, M$ and $\left|v_{k i}-\bar{v}_{k i}\right|<\eta$ for $i=1,2, \ldots, N_{k}^{\prime}, k=1,2, \ldots, K$.

2. We prove here the existence theorem for problem (I) in the following special case:

$$
\begin{aligned}
x_{n}^{\prime}(t)=f_{n}\left[t ; x_{1}(t), x_{1}\left(\varphi_{11}(t)\right), x_{1}\left(\varphi_{12}(t)\right), \ldots ;\right. & \\
x_{2}(t), & \left.x_{2}\left(\varphi_{21}(t)\right), x_{2}\left(\varphi_{22}(t)\right), \ldots ; \ldots\right] \quad(n=1,2, \ldots)
\end{aligned}
$$

with $x_{n}(0)=0, n=1,2, \ldots$ We introduce 
Assumpilion (A). Suppose that

$1^{n}$ the function $f_{n}: s_{2} \rightarrow(-\infty, \infty)(n=1,2, \ldots)$ is continumus,

$2^{\circ}$ there enists an $\eta^{\prime}>0$ such that

$$
\sup \left|f_{n}\left(t ; u_{11}, u_{12}, \ldots ; u_{21}, u_{22}, \ldots ; \ldots\right)\right| \leqslant \omega^{-1}
$$

for $n=1,2, \ldots, t \in[0, a], \quad\left|u_{i j}\right| \leqslant r, i, j=1,2, \ldots$,

$3^{0}$ the function $q_{i j}:[0, a] \rightarrow[0, a](i, j=1,2, \ldots)$ is continuous.

TH匹orEM 1. Cnder Assumption (A) there exists at least one solution of the initial-value problem (II); this solution consists of uniformly bounded contimuons functions on the interval $[0, a]$.

Proof. It is obvious that problem (II) is equivalent to the following infinite system of integral equations

$$
\begin{aligned}
\left.n_{n}(t)=\int_{0}^{t} f_{n} \mid s ; x_{1}(s), x_{1}\left(p_{11}(s)\right), x_{1}\left(p_{12}(s)\right), \ldots ; \ldots\right] d s & \\
& (n=1,2, \ldots)
\end{aligned}
$$

considered in $E$. We shall first prove that if $x_{i} \in G[0, a](i=1,2, \ldots)$, then the composition

$$
h(t)=f_{n}\left(t ; x_{1}(t), x_{1}\left(p_{11}(t)\right), \ldots ; x_{2}(t), x_{2}\left(\varphi_{21}(t)\right), \ldots ; \ldots\right)
$$

is continuous in the interval $[0, a]$. Let

$$
\begin{aligned}
& a_{k}=\left(t_{k} ; x_{1}\left(t_{k}\right), x_{1}\left(\varphi_{11}\left(t_{k}\right)\right), x_{1}\left(\varphi_{12}\left(t_{k}\right)\right), \ldots ; \ldots\right), \\
& a_{0}=\left(t_{0} ; x_{1}\left(t_{0}\right), x_{1}\left(\varphi_{11}\left(t_{0}\right)\right), a_{1}\left(\varphi_{12}\left(t_{0}\right)\right), \ldots ; \ldots\right) .
\end{aligned}
$$

Then for $\left(t_{k}\right) \rightarrow t_{0}, t_{k} \in[0, a]$ we get $\lim x_{i}\left(t_{k}\right)=x_{i}\left(t_{0}\right)$ and $\lim x_{i}\left(\varphi_{i j}\left(t_{k}\right)\right)$ $=x_{i}\left(\varphi_{i j}\left(t_{0}\right)\right)(i, j=1,2, \ldots)$. This means that $\lim \varrho_{2}\left(a_{k}, a_{0}\right)=0$. Hence $\left(h\left(t_{k}\right)\right) \rightarrow h\left(t_{0}\right)$ by the continuity of $f_{n}$.

If $T$ is an operator whose coordinates are defined by right-hand sides of system (1), and $\pi_{0}$ denotes the set consisting of $U=\left(x_{1}, \infty_{2}, \ldots\right) \in \mathbb{E}$ such that

$$
\begin{aligned}
\left\|x_{n}\right\| \leqslant r, \quad\left|x_{n}\left(t_{1}\right)-x_{n}\left(t_{2}\right)\right| \leqslant r a^{-1}\left|t_{1}-t_{2}\right| & \\
& \text { for } t_{1}, t_{2} \in[0, a] \text { and } n=1,2, \ldots,
\end{aligned}
$$

then $T: K_{0} \rightarrow K_{0}$. We shall prove now that the operator $T$ is continuous on $K_{0}$. Let $\left(U_{k}\right) \rightarrow U$, where $U_{k}=\left(x_{k 1}, a_{k 2}, \ldots\right), \quad U=\left(x_{1}, x_{2}, \ldots\right) \in K_{0}$. We must prove that

$$
\left\|y_{k n}-y_{n}\right\| \rightarrow 0 \quad \text { with } k \rightarrow \infty \quad(n=1,2, \ldots),
$$


where

$$
\begin{aligned}
y_{k n}(t) & =\int_{0}^{t} f_{n}\left[s ; x_{k 1}(s), x_{k 1}\left(\varphi_{11}(s)\right), x_{k 1}\left(\varphi_{12}(s)\right), \ldots ; \ldots\right] d s \\
y_{n}(t) & \left.=\int_{0}^{t} f_{n} \mid s ; x_{1}(s), x_{1}\left(\varphi_{11}(s)\right), x_{1}\left(\varphi_{12}(s)\right), \ldots ; \ldots\right] d s .
\end{aligned}
$$

Because $\lim \left|x_{n}(s)-x_{k n}(s)\right|=0$, for $\delta>0$ the number $N$ exists such that

$$
\begin{aligned}
& \sum_{n=1}^{\infty} 2^{-n}\left[2^{-1} \frac{\left|x_{k n}(s)-x_{n}(s)\right|}{1+\left|x_{k n 2}(s)-x_{n}(s)\right|}+\right. \\
& \left.\quad+\sum_{i=2}^{\infty} 2^{-i} \frac{\mid x_{k n}\left(\varphi_{n, i-1}(s)\left|-x_{n}\left(\varphi_{n, i-1}(s)\right)\right|\right.}{1+\mid x_{k n}\left(\varphi_{n, i-1}(s)\right)-x_{n}\left(\varphi_{n, i-1}(s) \mid\right)}\right]<\delta
\end{aligned}
$$

for $k>N$ and $s \in[0, a]$. By uniform continuity of the function $f_{n}$ on the set $Z_{1}=[0, a] \times m_{r} \times m_{r} \times \ldots$ we can find, for $\varepsilon>0$, such a number $N$ that

$$
\begin{aligned}
\left\{f _ { n } \left(s ; x_{k: 1}(s), x_{k: 1}\left(\varphi_{11}(s)\right)\right.\right. & \left., x_{k 1}\left(\varphi_{12}(s)\right), \ldots ; \ldots\right)- \\
& -f_{n}\left(s ; x_{1}(s), x_{1}\left(\varphi_{11}(s)\right), x_{1}\left(\varphi_{12}(s)\right), \ldots ; \ldots\right) \mid<\varepsilon
\end{aligned}
$$

whenever $k>N, s \in[0 ; a]$. Hence $\left|y_{k n}(t)-y_{n}(t)\right| \leqslant \varepsilon a$ for $k>N, t \in[0, a]$, $n=1,2, \ldots$ Thus $T$ is continuous in $K_{0}$. Since for $\left\|x_{i n}\right\| \leqslant v,\left|x_{i n}\left(t_{1}\right)-x_{i n}\left(t_{2}\right)\right|$ $\leqslant r a^{-1}\left|t_{1}-t_{2}\right|$, where $t_{1}, t_{2} \in[0, a], i=1,2, n=1,2, \ldots$ and for $0 \leqslant \alpha \leqslant 1$ we have

$$
\begin{gathered}
\left\|(1-\alpha) x_{1 n}+\alpha x_{2 n}\right\| \leqslant v, \\
\left.\mid(1-a) x_{1 n}\left(t_{1}\right)+a x_{2 n}\left(t_{1}\right)-(1-a) x_{1 n}\left(t_{2}\right)-\alpha x_{2 n}\left(t_{2}\right)\right] \leqslant r a^{-1}\left|t_{1}-t_{2}\right|,
\end{gathered}
$$

$K_{0}$ is a convex set. It can be easily proved that $K_{0}$ is compact. Indeed, let $\left(J_{i}\right)$ be an infinite sequence such that $\sigma_{i}=\left(x_{1}^{(i)}, x_{2}^{(i)}, \ldots\right) \in K_{0}$. Let $k$ be a fixed number. Let us consider the sequence $\left(x_{k}^{(i)}\right)$. The functions of the above sequence satisfy the inequality

$$
\left|x_{i}^{(i)}\left(t_{1}\right)-w_{i}^{(i)}\left(t_{2}\right)\right| \leqslant r a^{-1}\left|t_{1}-t_{2}\right| \quad(i=1,2, \ldots)
$$

for $t_{1}, t_{2} \in[0, a]$. Hence these functions are equally continuous and we know that they are uniformly bounded, thus we can apply the Arzelà theorem. Hence we can substract from the sequence $\left(x_{1}^{(i)}\right)$ a subsequence $\left(x_{1}^{n_{1}^{(i)}}\right)$ converging to some $x_{1}$. Similarly, from $\left(x_{2}^{n_{1}^{(i)}}\right)$ a subsequence $\left(x_{2}^{n_{2}^{(i)}}\right)$ converging to some $x_{2}$ ean be substracted. Amalogously we can 
verify that the sequence $\left(U_{n_{k}}(k)\right)$ is convergent to $U=\left(x_{1}, x_{2}, \ldots\right) \in K_{0}$, since

$$
\lim x_{i}^{n_{k}^{(k)}}(t)=x_{i}(t) \quad \text { uniformly in }[0, a]
$$

for every $i=1,2, \ldots$

Now, Theorem 1 is implied by the Tichomor fixed-point theorem.

Remark 1 . Theorem $I$ is a generalization of the result of paper [2], where a theorem on the existence of solutions of the equation

$$
a^{\prime}(t)=f\left(t, x(t), a\left(\varphi_{1}(t)\right), \ldots, x\left(\varphi_{n}(t)\right)\right)
$$

was established.

3. In this section we shall consider the initial-value problem for (I), under the following

Assuniption B. Suppose that

$1^{0}$ the function $f_{n}: s_{3} \rightarrow(-\infty, \infty)(n=1,2, \ldots)$ is continuous,

$2^{\circ}$ there exists a positive number $r$ such that

$$
\sup \left|f_{n}\left(t ; u_{11}, u_{12}, \ldots, \ldots ; v_{11}, v_{12}, \ldots, \ldots\right)\right| \leqslant v
$$

for $n=1,2, \ldots, t \in[0, a] ;\left|u_{i j}\right| \leqslant r a,\left|v_{i j}\right| \leqslant r, i, j=1,2, \ldots$,

$3^{0}$ the functions $f_{n}, n=1,2, \ldots$, are equally continuous on the set $Z_{2}=[0, a] \times Z^{\prime} \times Z^{\prime \prime}$, where $Z^{\prime}=m_{a r} \times m_{a r} \times \ldots, Z^{\prime \prime}=m_{r} \times m_{\tau} \times \ldots$,

$4^{0}$ there exist non-negative constants $\mu_{i j}^{(n)}(n=1,2, \ldots), i, j=1,2, \ldots$, such that the inequalities

$$
\begin{gathered}
\left|f_{n}(t, \xi, \eta)-f_{n}(t, \xi, \bar{\eta})\right| \leqslant \sum_{i=1}^{\infty} \sum_{j=1}^{\infty} \mu_{i j}^{(n)}\left|v_{i j}-\bar{v}_{i j}\right|, \\
\mu=\sup \left\{\sum_{i=1}^{\infty} \sum_{j=1}^{\infty} \mu_{i j}^{(n)}: n=1,2, \ldots\right\}<1,
\end{gathered}
$$

are satisfied for any $t \in[0, a], \xi, \eta=\left(v_{n}\right), \bar{\eta}=\left(\bar{v}_{n}\right) \epsilon s_{1}, v_{i}=\left(v_{i n}\right), \bar{v}_{i}=\left(\bar{v}_{i n}\right) \epsilon s$,

$5^{0}$ the functions $\varphi_{i j}:[0, a] \rightarrow[0, a], i, j=1,2, \ldots$, are equi-continuous,

$6^{\circ}$ the function $\psi_{i j}:[0, a] \rightarrow[0, a] \quad(i, j=1,2, \ldots)$ is continuous, $\tau^{\circ}$ for any $t_{1}, t_{2} \in[0, a]$ the following inequality holds

$$
\left|\psi_{i j}\left(t_{1}\right)-\psi_{i j}\left(t_{2}\right)\right| \leqslant\left|t_{1}-t_{.2}\right| \quad(i, j=1,2, \ldots) .
$$

TImonen 2. If Assumption (B) is satisfied, then there exists at least one solution of the initial-value problem (I); this solution consists of uniformly bounded continuous functions on the interval $[0, a]$. 
Proof. We reduce problem (I), by substitution $x_{n}^{\prime}(t)=\|_{n}(t)$ $(n=1,2, \ldots)$ to the following system of equations

$$
\begin{aligned}
& u_{n}(t)=f_{n}\left[t ; \int_{0}^{t} u_{1}(s) d s, \int_{0}^{\varphi_{11}(t)} u_{1}(s) d s, \int_{0}^{\varphi_{12}(t)} u_{1}(s) d s, \ldots ; \ldots\right. \\
& \left.u_{1}(t), u_{1}\left(\psi_{11}(t)\right), u_{1}\left(\psi_{12}(t)\right), \ldots ; \ldots\right] . \\
& (n=1,2, \ldots) \text {. }
\end{aligned}
$$

Let $T$ be the operator whose coordinates are defined by the righthand sides of system (2) and let

$$
K_{0}=\left\{U=\left(u_{1}, u_{2}, \ldots\right) \in E:\left\|u_{n}\right\| \leqslant \vartheta, n=1,2, \ldots\right\} .
$$

From Assumption (B) it follows that the operator $T$ is continuous in $K_{0}$, and $T: K_{0} \rightarrow K_{0}$.

Let $F_{n}: K_{0} \times[0, a] \times[0, a] \rightarrow(-\infty, \infty)(n=1,2, \ldots)$ be the function of variables $\delta=\left(u_{1}, u_{2}, \ldots\right) \in K_{0}, t, \tau \in[0, a]$. This function arises from the right-hand side of equation (2), if we replace in the last group of the terms

$$
u_{i}(t), \quad u_{i}\left(\psi_{i 1}(t)\right), \quad u_{i}\left(\psi_{i 2}(t)\right), \quad \ldots \quad(i=1,2, \ldots)
$$

the variable $t$ by $\tau$. Consider the restrictions of $f_{n}$ to the set $Z_{2}$; then for every $\varepsilon>0$ there exist $\eta(\varepsilon)>0$ and natural numbers $N_{1}^{(n)}, N_{2}^{(n)}, \ldots, N_{: I_{n}}^{(n)}$, such that

$$
\left|F_{n}\left(U, t_{1}, t_{1}\right)-F_{n}\left(U, t_{2}, t_{1}\right)\right|<\varepsilon
$$

for every $U \in K_{0}$ and every $t_{1}, t_{2} \in[0, a]$, for which

$$
\left|t_{1}-t_{2}\right|<\eta, \quad \vartheta\left|\varphi\left(t_{2}\right)-\varphi\left(t_{1}\right)\right|<\eta \quad \text { for all } \varphi \in \mathscr{F},
$$

where $\mathscr{F}$ denotes the set of functions:

$$
\begin{gathered}
\varphi_{1 j}, \quad j=1,2, \ldots, N_{1}^{(n)}-1 \quad(n=1,2, \ldots) \\
\ldots \ldots \ldots \\
\varphi_{M_{n_{n} j}}, \quad j=1,2, \ldots, N_{M n_{n}}^{(n)}-1 \quad(n=1,2, \ldots) .
\end{gathered}
$$

For our $\eta=\eta(\varepsilon)$ there exists $v=\nu(\eta)>0$, such that $v^{\prime}\left|\psi\left(t_{1}\right)-\psi\left(t_{2}\right)\right| \leqslant \eta$ for $\varphi \in \mathscr{F}$ and $\left|t_{1}-t_{2}\right|<\nu$. Therefore inequalities (3) hold for any $t_{1}, t_{2} \in\left[0, a_{1}\right]$, $\left|t_{1}-t_{\mathrm{a}}\right|<\delta$, where $\delta=\min \left(\eta, \eta{ }^{\gamma^{-1}}, \nu\right)$. Thus we see that: there exists a function $\delta:(0, \infty) \rightarrow(0, \infty)$ such that iff $U \in K_{0}, t_{1}, t_{2} \in[0, a],\left|t_{1}-t_{2}\right|$ $<\delta(\varepsilon)$, then

$$
\left|F_{n}\left(U, t_{1}, t_{1}\right)-F_{n}\left(U, t_{2}, t_{1}\right)\right|<\varepsilon \quad \text { for } \|=1,2, \ldots
$$


Consider the set $K_{0}^{\varepsilon}$ of those $U=\left(u_{1}, u_{2}, \ldots\right) \in K_{0}$ which have the following property: for every $\varepsilon>0$ and $t_{1}, t_{2} \in[0, a], \quad\left|t_{1}-t_{2}\right|<\delta(\varepsilon)$,

$$
\sup \left\{\left|u_{n}\left(t_{1}\right)-u_{n}\left(t_{2}\right)\right|: n=1,2, \ldots\right\} \leqslant(1-\mu)^{-1} \cdot \varepsilon
$$

holds.

Now we can prove the inclusion $T\left[K_{0}^{\varepsilon}\right] \subset K_{0}^{\varepsilon}$. In fact, if $U=\left(u_{1}, u_{2}, \ldots\right) \in K_{0}^{e}$ and $T U=\left(T u_{1}, T u_{2}, \ldots\right)$, then

$$
\begin{aligned}
& \left|T u_{n}\left(t_{1}\right)-T u_{n}\left(t_{2}\right)\right| \leqslant \varepsilon+\left|F_{n}\left(U, t_{2}, t_{1}\right)-F_{n}\left(U, t_{2}, t_{2}\right)\right| \\
& \left.\quad \leqslant \varepsilon+\sum_{i=1}^{\infty}\left[\mu_{i 1}^{(n)}\left|u_{i}\left(t_{1}\right)-u_{i}\left(t_{2}\right)\right|+\sum_{j=2}^{\infty} \mu_{i j}^{(n)} \mid u_{i}\left(\psi_{i_{, j}-1}\left(t_{1}\right)\right)-u_{i}\left(\psi_{i, j-1}\left(t_{2}\right)\right)\right]\right] \\
& \quad \leqslant \varepsilon+(1-\mu)^{-1} \varepsilon \sum_{i=1}^{\infty} \sum_{j=1}^{\infty} \mu_{i j}^{(n)} \leqslant \varepsilon+(1-\mu)^{-1} \varepsilon \mu=(1-\mu)^{-1} \varepsilon,
\end{aligned}
$$

for $\varepsilon>0$ and $\left|t_{1}-t_{2}\right|<\delta(\varepsilon)$.

Thus we see that the continuous operator $T$ maps the convex compact set $\Pi_{0}^{\varepsilon}$ into itself; therefore, according to Tichonor's fixed-point theorem there exists at least one fixed point of $T$. This fixed-point is evidently a solution of system (2).

Remark 2 . Theorem 2 is a generalization of a result from [2], where the existence of solutions of the equation

$$
x^{\prime}(t)=f\left(t, x(t), x\left(\varphi_{1}(t)\right), \ldots, x\left(\varphi_{n}(t)\right), x^{\prime}(t), x^{\prime}\left(\psi_{1}(t) \dot{j}, \ldots, x^{\prime}\left(\psi_{m}(t)\right)\right)\right.
$$

was established.

We shall formulate another theorem on the existence of a solution of problem (I).

Asstrampron (C). Suppose that

$1^{\circ}$ conditions $1^{\circ}, 3^{\circ},{1^{\circ}}^{\circ}, 5^{\circ}$ and $6^{\circ}$ of Assumption (B) are satisfied,

$2^{\circ}$ there exists a constant $q \geqslant 0$ such that

$$
\left|f_{n}(t, \xi, \theta)\right| \leqslant q \quad(n=1,2, \ldots)
$$

for any $t \in[0, a], \xi \in s_{1}$, where $\theta$ denotes the sero element of the space $s_{1}$.

TrEorem 3. If Assumption (C) is satisfied, then there exists at least one solution of the initial-value problem (I).

Proof. Let $T$ be the operator defined in the proof of Theorem 2 . Given $r>0$, the inequality $\left|T u_{n}(t)\right| \leqslant q+\mu r$ holds for all $U=\left(u_{1}, u_{2}, \ldots\right)$ $\epsilon E,\left|u_{n}(t)\right| \leqslant r(n=1,2, \ldots)$. Choosing $r_{0}>0$ so that $q+\mu r_{0} \leqslant r_{0}$, we see that $T: K_{0} \rightarrow K_{0}$, where

$$
K_{0}=\left\{U=\left(u_{1}, u_{2}, \ldots\right):\left\|u_{n}\right\| \leqslant r_{0}, n=1,2, \ldots\right\} .
$$

Then we proceed similarly as in the proof of Theorern 2. 
4. In this section we shall establish theorems on the existence of a unique solution of the initial-value problem (II).

Assuntrion (D). Suppose that

$1^{\circ}$ Assumption (A) is satisfied,

$2^{\circ}$ ther'e exists a function $g \in C[0, a]$ such that

$$
\left|f_{n}(t, \xi)-f_{n}(t, \bar{\xi})\right| \leqslant g(t) \cdot \sup \left\{\left|u_{i 1}-\bar{u}_{i 1}\right|,\left|u_{i 2}-\bar{u}_{i 2}\right|, \ldots: i=1,2, \ldots\right\}
$$

for every $n=1,2, \ldots, t \in[0, a], \xi=\left(u_{n}\right), \bar{\xi}=\left(\bar{u}_{n}\right) \epsilon s_{1}$, whore $u_{i}=\left(u_{i n}\right)$, $\bar{u}_{i}=\left(\bar{u}_{i n}\right) \epsilon s$,

$3^{0}$ the function $\varphi_{i j}(i, j=1,2, \ldots)$ fulfils the inequality

$$
\varphi_{i j}(t) \leqslant t \text { for every } t \in[0, a] .
$$

Assumpton (). Suppose that

$1^{\circ}$ conditions $1^{\circ}$ and $2^{\circ}$ of Assumption (D) are satisfied,

$2^{\circ} \quad a \cdot\|g\|<1$.

THEOmen 4. Under Assumption (D) there exists a nnique solution of problem (II). This solution consists of uniformly bounded and equi-continuous functions defined on the interval $[0, a]$; it is the limit of the sequence of Picard's sucoessive approximations

$$
\begin{aligned}
& x_{n}^{(0)}(t)=0, \\
& x_{n}^{(k)}(t)=\int_{0}^{t} f_{n}\left[s ; x_{1}^{(k-1)}(s), x_{1}^{(k-1)}\left(p_{11}(s)\right), x_{1}^{(k-1)}\left(\varphi_{12}(s)\right), \ldots ;\right. \\
& x_{2}^{(k-1)}(s), x_{2}^{(k-1)}\left(\varphi_{21}(s)\right), x_{2}^{(k-1)}\left(\varphi_{22}(s)\right), \ldots ; \\
& \ldots \ldots \ldots \ldots . \ldots \ldots d s \\
& \text { for } k=1,2, \ldots(n=1,2, \ldots)
\end{aligned}
$$

Proof. For any fixed $n$, let us consider the sequence $\left(x_{n}^{(k)}\right)$ of the functions defined by formulas (4). The functions are continuous and bounded by $r$ on the interval $[0, a]$, and

$$
\left|x_{n}^{(k+1)}(t)-x_{n}^{(k)}(t)\right| \leqslant \frac{v^{\bullet}\|g\|^{k}|t|^{k+1}}{a(k+1) !} \leqslant \frac{\vartheta(\|g\| a)^{k}}{(k+1) !}
$$

Since the series

$$
x_{n}^{(0)}+\left(x_{n}^{(1)}-x_{n}^{(0)}\right)+\ldots+\left(x_{n}^{(k+1)}-x_{n}^{(k)}\right)+\ldots
$$

is uniformly convergent on $[0, a]$, we also have

$$
\lim x_{n}^{(k)}(t)=x_{n}(t) \quad \text { unifoimly on }[0, a] .
$$

Now it is easily seen that the functions $x_{n}, n=1,2, \ldots$, satisfy system (1). 
Since

$$
\begin{aligned}
& \left|x_{n}^{\prime}(t)\right| \leqslant\left|f_{n}(t ; 0,0, \ldots ; 0,0 \ldots ; \ldots)\right|+ \\
& \quad+g(t) \sup \left\{\left|x_{i}(t)\right|,\left|x_{i}\left(\varphi_{i 1}(t)\right)\right|,\left|x_{i}\left(\varphi_{i 2}(t)\right)\right|, \ldots: i=1,2, \ldots\right\} \\
& \leqslant r a^{-1}+\|g\| r \quad(n=1,2, \ldots),
\end{aligned}
$$

our solution of (1) consists of equi-continuous functions.

Suppose that $\left(x_{1}, x_{2}, \ldots\right)$ and $\left(y_{1}, y_{2}, \ldots\right)$ are two solutions of (1). By (5), for every $n$ we have

$$
\left|y_{n}(t)-x_{n}^{(k)}(t)\right| \leqslant \frac{v \cdot\|g\|^{k}|t|^{k+1}}{a(k+1) !} \leqslant \frac{r(\|g\| a)^{k}}{(k+1) !}
$$

for $t \in[0, a], k_{i}=0,1,2, \ldots$ Hence $y_{n}(t)=\lim x_{n}^{(k)}(t)=x_{n}(t)$ for $n=$ $=1,2, \ldots$ Thus completes the proof.

Let us further state

THEOrem 5. Under Assumption (E) the conchusion of Theorem \pm is valid and, moreover, if $x_{n}^{(k)}(n=1,2, \ldots)$ ave defined by formulas (4), then

$$
\left|w_{n}(t)-w_{n}^{(k)}(t)\right| \leqslant \imath \cdot a^{k}\|g\|^{k}
$$

for $t \in[0, a], k=0,1,2, \ldots$

5. We now want to formulate a theorem on the existence and uniqueness of the solution of problem (I).

Assumiption (F). Suppose that

$1^{\circ}$ conditions $1^{\circ}, 2^{\circ}$ and $6^{\circ}$ of Assumption (B) ave satisfied,

$2^{0}$ the function $p_{i j}:[0, a] \rightarrow[0, a](i, j=1,2, \ldots)$ is continuous,

$3^{\circ}$ there exist functions $g_{1} \in G[0, a]$ and $g_{2} \in C[0, a]$ such that

$$
\begin{aligned}
& \left|f_{n}(t, \xi, \eta)-f_{n}(t, \bar{\xi}, \bar{\eta})\right| \\
& \leqslant g_{1}(t) \sup \left\{\left|u_{i 1}-\bar{u}_{i 1}\right|,\left|v_{i 2}-\bar{u}_{i 2}\right|, \ldots: i=1,2, \ldots\right\}+ \\
& \quad+g_{2}(t) \sup \left\{\left|v_{i 1}-\bar{v}_{i 1}\right|,\left|v_{i 2}-\bar{v}_{i 2}\right|, \ldots: i=1,2, \ldots\right\}
\end{aligned}
$$

for $n=1,2, \ldots, t \in[0, a], \xi=\left(u_{n}\right), \eta=\left(v_{n}\right), \bar{\xi}=\left(\bar{u}_{n}\right), \bar{\eta}=\left(\bar{v}_{n}\right) \epsilon s_{1}$, where $u_{i}=\left(u_{i n}\right), v_{i}=\left(v_{i n}\right), \bar{u}_{i}=\left(\bar{u}_{i n}\right), \bar{v}_{i}=\left(\bar{v}_{i n}\right) \in \mathcal{S}$,

$4^{\circ} a\left\|g_{1}\right\|+\left\|g_{2}\right\|<1$.

THEORgn 6. Under Assumption (F) there exists a unique solution of problem (I). This solution consists of uniformly bounded and equi-continwous functions defined on the interval $[0, a]$; it is the limit of the sequence 
of Picard's successive approximations

$$
\begin{aligned}
& x_{n}^{(0)}(t)=0, \\
& x_{n}^{(k)}(t)=\int_{0}^{t} f_{n}\left[s ; x_{1}^{(k-1)}(s), x_{1}^{(k-1)}\left(\varphi_{11}(s)\right), x_{1}^{(k-1)}\left(\varphi_{12}(s)\right), \ldots ;\right. \\
& x_{2}^{(k-1)}(s), x_{2}^{(k-1)}\left(\varphi_{21}(s)\right), x_{2}^{(k-1)}\left(\varphi_{22}(s)\right), \ldots ; \\
& \dot{x}_{1}^{(k-1)}(s), \dot{x}_{1}^{(k-1)}\left(\psi_{11}(s)\right), \dot{x}_{1}^{(k-1)}\left(\psi_{12}(s)\right), \ldots ; \\
& \dot{x}_{2}^{(k-1)}(s), \dot{x}_{2}^{(k-1)}\left(\psi_{21}(s)\right), \dot{x}_{2}^{(k-1)}\left(\psi_{22}(s)\right), \ldots ; \\
& \text {............. } \mid d s, \\
& \text { for } k=1,2, \ldots(n=1,2, \ldots)
\end{aligned}
$$

Proof. For any fixed $n$, let us consider the sequence $\left(x_{n}^{(k)}\right)$ of the functions defined by formulas (7), and the sequence $\left(\dot{x}_{n}^{(k)}\right)$ of their derivatives. Since

$$
x_{n}^{(k)}(t)-x_{n}^{(k-1)}(t)=\int_{0}^{t}\left[\dot{x}_{n}^{(k)}(s)-\dot{x}_{n}^{(k-1)}(s)\right] d s,
$$

it easily follows that

$$
\left\|\dot{x}_{n}^{(k+1)}-\dot{x}_{n}^{(k)}\right\| \leqslant\left(a\left\|g_{1}\right\|+\left\|g_{2}\right\|\right) \sup \left\{\left\|\dot{x}_{i}^{(i)}-\dot{x}_{i}^{(k-1)}\right\|: i=1,2, \ldots\right\} .
$$

Hence, by induction on $n$,

$$
\left\|\dot{x}_{n}^{(k+1)}-\dot{x}_{n}^{(k)}\right\| \leqslant 2 \eta\left(a\left\|g_{1}\right\|+\left\|g_{2}\right\|\right)^{k-1} .
$$

From (8) and (9) it follows that

$$
\left\|x_{n}^{(k)}-x_{n}^{(k-1)}\right\| \leqslant 2 r a\left(a\left\|g_{1}\right\|_{1}+\left\|g_{2}\right\|\right)^{k-2},
$$

therefore the series

$$
x_{n}^{(0)}+\sum_{k=1}^{\infty}\left(x_{n}^{(k)}-x_{n}^{(k-1)}\right), \quad \dot{x}_{n}^{(0)}+\sum_{k=1}^{\infty}\left(\dot{x}_{n}^{(k)}-\dot{x}_{n}^{(k-1)}\right)
$$

are uniformly convergent on $[0, a]$, provided that $a\left\|g_{1}\right\|+\left\|g_{2}\right\|<1$. Hence

$$
\lim x_{n}^{(k)}(t)=\dot{x}_{n}(t), \quad \lim \dot{x}_{n}^{(k)}(t)=\dot{x}_{n}(t)
$$

uniformly on $[0, a]$.

Continuing similarly as in the proof of Theorem 4, we verify that the limit functions $x_{n}, n=1,2, \ldots$ satisfy the following system of integral equations

$$
\begin{aligned}
x_{n}(t)=\int_{0}^{t} f_{n}\left[s ; x_{1}(s), x_{1}\left(\varphi_{11}(s)\right), x_{1}\left(\varphi_{12}(s)\right), \ldots, \ldots\right. & \ldots \ldots \\
\ldots & \ldots \ldots \ldots . \ldots \ldots
\end{aligned}
$$

and have all the properties asserted in the theorem. 


\section{Referenceg}

[1] A. Alexiewicz, Analiza funkivonalna, Warszawa 1909.

[2] M. Kwapisz, On certain differential equations with deviated argument, Praco Mat. 12 (1908), p. 23-29.

[3] Б. В. Логинов, Х. Р. Р ахматова, О бесконеиных системьах интееро-диффреренциальиых уравнений, Сб. „Краевые задачи для дифференциальных уравненің年 с тастными производнымп", Ташкент 1970, p. 100-109.

[4] S. Mazur et W. Orlicz, Sur les espaces métriques linénires (I), Studia Math. 10 (1948), p. 184-208.

[5] К. Л. Персипскпї, Об устойчивости ремений счетной системь дифференұиальных уравнений, Изв. Каз ССР, серия матем. и мех. 2 (1948), р. 3-34.

[6] - Счетные системи дифберенциальных уравнений и успойчивость их решений, Нав. AH Каз ССР, серия матем. и мех. 7 (11) (1959); 8 (12) (1959); 9 (13) (1961).

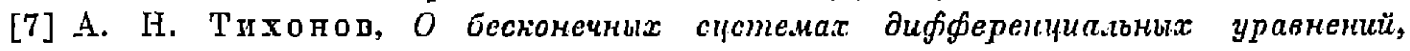
Матем. сб. 41 (1934), p. 556-560.

[8] A. N. Ticlionov, Ein Fixpunktsatz, Math. Ann. 111 (1935), p. 707-776.

[9] 0. A. अli аутыков, о систной систене дифференциальных ураннений, соgермсаией перемениые парамиетры, Матем. сбі. 49 (91:3) (1959), р. 317-320.

Resu par la Rédaction le $21.7 .19 \% 3$ 